\title{
AS MANIFESTAÇÕES FESTIVAS RELIGIOSAS DO SÍTIO MINGUIRIBA-CRATO-CE
}

\section{THE RELIGIOUS FESTIVAL OF THE MINGUIRIBA SITE - CRATO-CE}

\author{
Francisca Eugenia Gomes Duarte \\ Ariluci Goes Elliott ${ }^{b}$ \\ Francisca Pereira dos Santosc
}

\begin{abstract}
RESUMO
Introdução: Apresenta as festas religiosas como eventos simbólicos associando a cultura e a identidade no âmbito das Ciências Sociais. A construção de uma identidade, com traços pertinentes ao coletivo denotados nas representações são elementos ricos e significantes ligados à memória individual ou coletiva, como costumes, saberes, lugares, ritmos, festejos, lendas e ritos que, ao serem adotados por um grupo, se perpetuam e se tornam fontes de identidade. Objetivo: expor as renovações do Sagrado Coração de Jesus no Sítio Minguiriba como narrativas das memórias dos acontecimentos cotidianos do passado e do presente. Metodologia: foi uma revisão bibliográfica e entrevistas realizadas com os moradores do Sítio. Resultados: expor os resultados obtidos. Conclusões: concluí-se que as manifestações religiosas conservam o sentimento de pertencimento de um grupo e criam um elo que dá sustentabilidade à memória coletiva.
\end{abstract}

Descritores: Memória. Manifestações Religiosas. Sítio Minguiriba - Crato - Ceará.

\section{INTRODUÇÃO}

A amplitude interdisciplinar da Biblioteconomia como parte integrante da Ciência da Informação permite que a aquisição do conhecimento tenha colheita

\footnotetext{
a Professora da Universidade Regional do Cariri (URCA). Mestre em Biblioteconomia, pela Universidade Federal do Cariri (UFCA). E-mail: eugenia.duarte@hotmail.com

b Professora do Curso de Biblioteconomia e do Programa de Pós-Graduação em Biblioteconomia da Universidade Federal do Cariri (UFCA). Doutora em Ciência da Informação, pela Universidade Estadual Paulista (UNESP/Marília). E-mail: ariluci.goes@ufca.edu.br

c Professora de Biblioteconomia e do Programa de Pós-Graduação em Biblioteconomia (PPGB) da Universidade Federal do Cariri (UFCA). Doutora em Literatura e Cultura, pela Universidade Federal da Paraiba (UFPB). E-mail: teiadoato@gmail.com
} 
farta em diversos campos científicos ao integrar o material e o social e incorporar "múltiplas dimensões, como a sociológica, situacional, política, filosófica, linguística, emocional, cultural, histórica e epistemológica". Campos e Venâncio (2006, p.1) trazendo para os estudos contribuições que permitem aprofundar conceitos de temas variados como cultura, identidade, memória, educação, dentre outros.

A cultura e a identidade, são termos que vêm sendo constantemente associados ao âmbito das Ciências Sociais. Os problemas relativos à identidade são atribuídos à cultura; as crises culturais são remetidas às questões identitárias e parte dessa problemática é situada na globalização econômica. Ideologias diversas, surgidas nos anos setenta opunham-se a multiculturalidade e segregavam as diferenças com o claro intuito de preservar a identidade. Não podemos, porém, ignorar que "a cultura pode existir sem a consciência da identidade" ao mesmo tempo que "as estratégias de identidade podem manipular e modificar uma cultura que não terá então quase nada em comum com o que ela era anteriormente" (CUCHE, 1999, p. 175-176). Nesse contexto, com luz em diversos autores que abordam a problemática, podemos afirmar que as festas religiosas atestam manipulações que transformaram a cultura identitária de diversas nações desde o séc. XVII e são pilares fortes para a formação da memória social.

A memória social é a esfera onde "uma sociedade representa para si mesma a articulação de seu presente com o seu passado, configurando em consequência, o modo pelo qual os indivíduos sociais representam a si próprios, as suas produções e as relações que estabelecem com os demais" (WOODWARD, 2000 apud GONDAR, 2015, p. 22) pois "Os grupos sociais possuem regras, ideias e elaboram informações próprias ao longo da sua história e sob o reflexo das diferentes relações que estabelecem" (ARAÚJO, 2008, p. 100).

Dessa forma há a construção da sua identidade, com traços pertinentes ao coletivo denotados nas representações que são elemento ricos e significantes ligados à memória individual ou coletiva, como costumes, saberes, lugares, ritmos, festejos, lendas e ritos que, ao serem adotados pelo grupo, se perpetuam 
e se tornam fontes de identidade e servem de veículo para memória do povo local em toda a sua pluralidade (MADEIRA, 2017) sendo que a cultura é reflexo da sociedade e através dela é possível distinguir quem são e o que fazem, seus valores, significados, significações e sentidos, traços identitários que os distinguem dos outros. Arias (2002); Hall, (1997). Para Cancline (2015) esse conjunto de bens e práticas tradicionais que nos identificam como nação ou como povo é apreciado como um dom, algo que recebemos do passado com tal prestígio simbólico que não cabe discuti-lo. As únicas operações possíveis preservá-lo, restaurá-lo, difundi-lo - são a base mais secreta da simulação social que nos mantém juntos (CANCLINE, 2015, p. 160).

As festas religiosas são eventos simbólicos repetidos anualmente. os rituais das festas religiosas, "são capazes de manifestar aquilo que se deseja tornar perene numa sociedade" (CORDEIRO, 2011, p. 109). A repetição desses eventos favorece o trabalho de solidificação da memória e impossibilita a ocorrência de alterações das lembranças (POLLAK,1992).

As festas são responsáveis pela sedimentação da cultura e criação de identidades individuais e coletivas, dessa forma potencializam a formação da história da comunidade, pois, na "memória de um grupo se destacam as lembranças dos eventos e das experiências que dizem respeito à maioria de seus membros e que resultam de sua própria vida ou de suas relações com os grupos mais próximos [...]"(HALBWACHS, 2003, p. 51). Portanto, as festas estão entre "os eventos fora do dia-a-dia, contextualizadas na condição de situações extraordinárias e previstas, construídas pela e para a sociedade e cuja passagem entre o universo cotidiano é marcado por mudanças de comportamento que tornam os eventos extraordinários especiais" (CORDEIRO, 2011, p.109).

O binómio festa/identidade é uma subespécie do binómio mais lato cultura/identidade, alimentando-se ambos de uma causalidade circular: porque já está identificado, o grupo festeja e, por sua vez, a festa cria ou reforça a identidade. Festa e identidade precedem-se mutuamente, são ambas factor e resultado, causa e efeito, mas em patamares e momentos diferenciados, num processo inacabado de identificação e de reinvenção celebrativa. Este processo, 
confirmado pela história e explorado pelas ciências humanas, radica na dimensão simbólica do homem, cuja auto-realização ou existência (pessoal e comunitária) só é possível por mediações (TEIXEIRA, 2010, p.18).

$\mathrm{Na}$ construção desse universo, como que montando um quebra-cabeças que retrate, com peças da memória popular, traços da identidade dessa comunidade, encontramos as manifestações festivas que ocorrem no Sítio Minguiriba, dentre as quais destacamos a realização da renovação.

A cidade do Crato, localizada ao sul do Ceará, geograficamente está situada a $7^{\circ} 14^{\prime} 03^{\prime \prime}$ de latitude ao sul e $39^{\circ} 24^{\prime} 34^{\prime \prime}$ de longitude a oeste, possui uma área de 1.117,5 km² (IPECE, 2016), limita-se ao norte com as cidades de Caririaçu e Farias Brito, ao sul com o estado de Pernambuco e Barbalha, a leste com Juazeiro do Norte e Caririaçu e a oeste com o estado do Pernambuco e as cidades de Nova Olinda e Santana do Cariri.

A pesquisa aqui apresentada foi realizada no Sítio Serra da Minguiriba, comunidade rural pertencente à cidade de Crato, situada na fronteira com o Município de Santana do Cariri e, de acordo com Brito (2015) está localizada no Distrito de Campo Alegre, setor oriental (porção leste) da Chapada do Araripe, com altitude que varia de 870 a 974 metros.

No meio rural, sendo poucas as oportunidades de lazer e entretenimento, as festas religiosas têm a participação de um número significativo de moradores e visitantes e exercem um papel de suma importância para a sociedade local. Nesses eventos sociais a comunidade se reúne para colocar os assuntos em dia e se divertir. Nesse contexto, os momentos festivos contribuem para a formação de novas identidades mediados pelo processo contínuo de construção e modificação dos saberes associadas ao movimento do tempo e à troca de conhecimento ocorrida no convívio com o grupo. O poder articulador da informação auxilia na identificação das características identitárias ao agregarem a memória coletiva e social elementos como músicas, narrativas, poesias, profissão, culinária, etc.

As fontes consultadas e o contato direto com os moradores do Sítio Minguiribapouco a pouco trazem à luz o conhecimento de peculiaridades que nos permitem compreender e registrar a história da comunidade através da 
memória oral dos personagens e de outros documentos que auxiliaram na construção da nossa pesquisa.

\section{A CONSAGRAÇÃO DO SAGRADO CORAÇÃO DE JESUS}

No século XVII, em Paray-leMonial, na França, em um convento de freira da Ordem de Visitação de Maria, Segundo Sampaio (2002) a partir das aparições de Jesus Cristo para Santa Margarida Maria Alaco que foi introduzido nas igrejas o culto da devoção do Coração de Jesus.

O filho de Deus, em aparições faz, a Santa Margarida, três revelações:

- Na primeira revelação aparece radiante como o sol, elevado em uma cruz, com uma coroa de espinho e ao descobrir o peito mostra a "santa" o "dulcíssimo coração" (BELTRAMI, 1932, p.35).

- na segunda revelação Jesus novamente apresenta-se a ela "todo radiante de glória" e mostrar-lhe o coração que "ardia como uma fornalha" (BELTRAMI, 1932, p.36).

- A terceira revelação é a união dos três corações (BELTRAMI, 1932).

Nesta aparição "Pediu-Ihe, então Jesus que fizesse estabelecer na Igreja uma festa especial para honrar o seu Divino Coração" e Ihe diz: "[...] eu te prometo que o meu Coração se dilatará para expandir com abundância as riquezas do seu amor sobre todos aqueles que lhe prestarem essa honra ou procurarem que por outrem Ihe seja prestada (BELTRAMI, 1932, p. 39). Margarida confidencia os detalhes dessa aparição ao Padre de laColombière que, após ouvi-la pede-lhe que o entregue por escrito esta declaração para que pudesse reler e refletir sobre a mesma.

Após a leitura tranquilizou a freira dizendo que poderia confiar que aquela era uma mensagem de Deus. "Margarida ajoelhou-se diante do Coração Divino e consagrou-se solenemente a Ele, prestando-Ihe por primeira uma das mais puras homenagens. O Venerável Padre de laColombière uniu-se a ela consagrando-se também ao Coração de Jesus, esse fato ocorreu numa sextafeira, 21 de junho do 1675" (BELTRAMI, 1932, p. 40). Segundo Sampaio (2002) nas revelações Jesus havia feito 12 promessas em favor de seus devotos: 
Conceder-Ihes-ei todas as graças necessárias ao seu estado; a paz nas suas famílias. A consolação nas suas penas; serei seu refúgio seguro durante a vida e sobretudo na morte; derramarei abundante bênçãos sobre todas as suas empresas; os pecadores acharão em mim a fonte e o oceano infinito da misericórdia; as almas tíbias se tornarão fervorosas; as almas fervorosas se elevarão rapidamente a grande perfeição; abençoarei eu mesmo as casas onde a imagem do meu coração estiver exposta e venerada; darei aos Sacerdotes o dom de abrandar os corações mais endurecidos; as pessoas que propagarem esta devoção terão escritos os seus nomes no meu coração, e dele nunca serão apagados; concederei no excesso da misericórdia do meu amor poderoso a graça da perseverança final aos que comungarem na primeira sexta-feira de nove meses seguidos. (MANUAL DO CORAÇÃO DE JESUS, 1962 apud SAMPAIO, 2002, p.11).

Havia na época o costume de se comemorar o onomástico, festa considerada tão ou mais importante que o aniversário, onde a pessoa que tinha o nome de um santo, comemoravam a data (BUENO, 2008). Dia 20 de Julho era o dia de Santa Margarida e as noviças resolveram fazer uma surpresa a Margarida, na época Diretora do convento, a realização de uma festa em comemoração ao seu onomástico. Tendo percebido as intenções das moças esta pediu que todas as honras fossem dedicadas ao Coração de Jesus. Atendendo ao pedido da Superior as noviças,

Transformaram em pequeno oratório uma salinha, forrando-lhe as paredes de flores, de estrelas e corações inflamados. Levantaram um altar, ornaram-no de rosas e lírios e no meio colocaram a imagem do Coração de Jesus, devoção já introduzida no noviciado pela sua Mestra (BELTRAMI, 1932, p. 49).

As características narradas assemelham-se as características da "sala do santo" encontrada nas residências nordestinos e reforça a ideia de que esse costume foi trazido pelo Padre Cícero para os lares nordestinos quando este foi à Roma em busca da revogação da proibição do bispo da cidade do Crato de rezar as missas na igreja católica (TOLOVI, 2011). A citação abaixo evidencia a nossa impressão:

No Nordeste e, principalmente em Juazeiro do Norte, a "sala do Santo" se encontra presente em quase todos os lares. Um pequeno altar é organizado na sala onde se faz o ritual tradicional da entronização do Coração de Jesus. Um ritual implantado e incentivado por padre Cícero. Essa Entronização geralmente é feita marcando uma data especial na família. De preferência a dada do casamento. Todos os anos, na mesma 
data, ocorre o ritual denominado "renovação". É o momento de renovar e fortalecer a devoção ao Coração de Jesus. Simbolicamente, a presenta do Coração de Jesus na família representa uma forma de proteção e presença constante do Divino. E neste espaço há um lugar reservado de forma especial para a imagem de padre Cícero - chamado carinhosamente por "meu padim" (TOLOVI, 2011, p. 223).

A renovação é realizada anualmente nos lares da zona urbana ou rural desde a época que o Padre Cícero era vivo, há mais de um século atrás, até os dias de hoje e, por ser um costume fortemente arraigado à cultura e a identidade do povo do Sítio Minguiriba, podemos em hipótese prever que o mesmo seguirá adiante por muitos e muitos anos, talvez permaneça para a posteridade, adaptando-se, como vem feito até então, as exigências de cada época.

Esse tipo de festa se popularizou na nossa região com os adventos da romanização do catolicismo popular, inicialmente realizada nas igrejas católicas, depois passou a ser realizada pelos padres nas residências dos fiéis e passou a ser chamada de Renovação do Coração de Jesus. Com o tempo os padres deixaram de ser figuras essenciais no ritual e a tarefa de realizar os ritos foi gradualmente sendo assumido por mulheres. Nesse sentido "O ritual da Consagração e Renovação do Sagrado Coração nos lares católicos constitui um rito de passagem, no qual o sagrado toma o lugar do profano" (FERNANDES 2005, apud ARAÚJO, 2011, p. 73).

Guilouski e Costa (2012); Santos (2015) consideram que O ritual traz a possibilidade de contato com o Espírito Santo. O Cariri Cearense configura-se a cada dia como um espaço manifestuoso de aproximações com o divino (SANTOS, 2015) repleto de lugares de memória onde constantemente as lembranças do passado se misturam com as do presente (BAUMAN, 2003), um campo onde a religiosidade popular está relacionada a festas e as "Renovações" funcionam como um "[...] fortalecimento da fé, renovação dos votos diante do santo, renovação da esperança diante das adversidades da vida, etc" (TOLOVI, 2017, p. 170).

As renovações foram descritas por Araújo (2011, p. 71) como um ritual católico, realizado em uma data simbólica para a família anfitriã, "pois sempre está relacionada ao aniversário de casamento da família ou do nascimento do primogênito". 
Não podemos deixar de lembrar que no Nordeste estes ritos foram abraçados pelo catolicismo popular que, contrariando as manifestações da igreja católica romanizada, especialmente nos rituais realizados no Sítio Minguiriba, têm como convidado de honra, compartilhando o altar ou a parede de imagens dos santos tradicionais, a representação de Padre Cícero Romão Batista, "o santo" excomungado pela igreja católica e entronizado e considerado santo pelo povo e idealizador da festa no Cariri Cearense (TOLOVI, 2017). Amado e idolatrado pela comunidade, o "padim", como é carinhosamente chamado, não poderia faltar a esse momento especial e não fica "no sol", entra em todos os lares, ocupa um lugar especial e, assim como ao Coração de Jesus, a ele também são rendidas homenagens, sem disputas e sem preferência, e é acolhido no altar pelo filho de Deus, já que cumprira a ordem dada por Jesus, em sonho, de cuidar daquele povo Cordeiro (2011); Guimarães (2011); Tolovi (2017).

$\mathrm{Na}$ contemporaneidade, homens voltam a conduzir a renovação, ficando a escolha, (que também pode ser uma mulher), critério dos donos da casa, assim como a data da celebração, realizada com a presença de convidados que homenageiam anualmente uma data especial do passado daquela família. Percebemos nesses eventos que "A identidade, sempre dinâmica, precisa de um sujeito que represente para si e para o outro uma maneira de se colocar no mundo, seja por suas atividades, discursos e memórias recontadas" (CRUZ, 2014 , p. 10). As Renovações, nesse contexto, funcionam como divisoras de águas no que se refere aos traços identitários. Estas festas evidenciam em suas práticas as mudanças ocorridas através dos tempos, tanto com os sujeitos quanto na própria prática do ritual híbrido, trazido pelo Padre Cícero da Europa e adaptado a realidade do sertão. Segundo o Padre Paulo

[...] a origem da renovação foi o Padre Cícero que trouxe, uma vez que o Padre Cícero Romão Batista ele viu isso na Itália. Essa espiritualidade... e como ele era um homem muito de... que viajava muito, que se informava muito então ele trouxe isso para a Região do Cariri e essa espiritualidade então se espalhou pela Região do Cariri, tanto é que só nós aqui conhecemos, essa espiritualidade da renovação do Coração de Jesus (Depoimento de Pe. Paulo, 2018). 
Mudanças ocorridas no século XX alteraram o modo de ser, de viver e agir do homem, favorecendo a mutação cultural com a diminuição das distâncias e o fluxo intensivo de informações que contribuem para a formação de identidades híbridas (CANCLINE, 2015), em comunidades que imperceptivelmente adotam uma cultura plural ao agregar novos conhecimentos aos costumes locais descentra, fragmenta e gera conflitos identitários (CANNEVACCI,1996) A globalização contribui para a fragmentação cultural e faz surgir, cada vez mais, uma "sociedade líquida", por ter tornado incertas e transitórias as identidades dos grupos sociais (BAUMAN, 2005) e, cada vez mais, contribui para as alterações culturais em comunidades e identidades na pós-modernidade.

As manifestações festivas remetem a uma identidade sempre em formação ao agregar, desde os primórdios, traços culturais trazidos pelos romeiros oriundos de diversos estados do país, e da Europa pelo Padre Cícero (Renovação do Coração de Jesus). Embora fragmentadas e naturalmente modificadas com a evolução do tempo, é através destes festejos que a comunidade mantém uma unidade identitária, se fortalece socialmente e vai ao encontro do futuro, seguindo os passos daqueles que no passado trilharam os mesmos caminhos em busca de uma vida melhor.

\section{AS RENOVAÇÕES DO SAGRADO CORAÇÃO DE JESUS NO SÍTIO MINGUIRIBA}

Há mais de 100 no Cariri, a Consagração do Sagrado Coração de Jesus, popularmente conhecida por "Renovação do Sagrado Coração de Jesus", eram realizados nas igrejas, por padres, porém, com o passar do tempo os costumes mudaram e as residências e os rituais passaram a ser celebrados por mulheres. No Sitio Minguiriba estes eventos seguem um ritual particular repetido em todos os lares que mantem, em aspectos gerais, a identidade secular das Renovações realizadas nas famílias e passada de geração para geração através da tradição oral que se consolidou no meio social através da recitação e da dramatização litúrgica.

Durante muitos anos um padre de Juazeiro realizava o ritual da renovação na casa de seu Antônio Inácio, depois de sua morte, o seu 
acompanhante responsabilizou-se pela tarefa: "Padre Murilo de Juazeiro. Conheceu? Ele era quem vinha celebrar a missa aqui todo ano. E ainda hoje celebra. Ele mesmo não, mas outro ficou celebrando" e em seu linguajar simples nos explicou que o que era a Renovação do Coração de Jesus: "A renovação é rezar a reza do santo todo ano. Celebrar a missa, comida pra todo mundo que chegar... Muito bom!" (Depoimento de Antônio Inácio, set, 2017).

Segundo pesquisas de Araújo (2011), a origem da simbologia que edifica o ritual remete à Idade Média com a Consagração dos lares ao Sagrado Coração de Jesus. Tolovi (2017) é de opinião que

[...] Todos os ritos e gestos de adoração inscrevem-se no marco social que lhes dá sentido e que, ao mesmo tempo, é reforçado pelo ambiente social. Os próprios mitos são consolidados e penetram na consciência por efeito de sua manifestação social (tanto na recitação quanto na dramatização litúrgica) (CROATTO, 2010 apud TOLOVI, 2017, p. 142).

De acordo com o costume trazido da Europa, no passado, às Renovações do Sagrado Coração de Jesus eram realizadas em homenagem a uma data especial: o aniversário de um filho, de um familiar ou a data do casamento dos donos da casa. No Sítio Minguiriba, nos dias atuais, de acordo com as fontes consultadas, as Renovações são realizadas em comemoração ao aniversário de casamento dos donos da casa ou ao nascimento do primogênito. Percebemos, no entanto, que, no Sítio Minguiriba, não há um motivo especial para a realização das Renovações do Sagrado Coração de Jesus. Observamos, porém, que muito dos moradores fazem a opção de realizar a consagração de seus lares nos dias de São João ou Natal e de santos de sua devoção como São José, São Francisco e Santa Luzia, ou pelos motivos antes identificados relativos a casamentos e natalícios. A sincronização das duas festas torna essas datas especiais para os moradores que participam do festejo. Encontramos até quem realiza a renovação como pagamento de promessa feita para o santo de devoção pela cura de uma enfermidade, segundo Seu Horácio, há aproximadamente 30 anos sua irmã fez uma promessa para que ficasse curado e desde então realizam a renovação em sua casa:

Tem uns vinte anos, não ...tem mais. Uma base de uns trinta anos. Ela fez uma promessa. Eu fui operado e uma irmã disse assim que... que fazia uma promessa para mim, pra eu ficar bom. Lá no hospital. Ela perguntou pelos santos. Eu disse: É 
Deus no céu e Nossa Senhora na terra, o Coração de Jesus, lá vai. Ela fez pra eu não comer carne na Sexta Feira da Paixão e jejuar. Rezar uma novena aí. Rezar o terço, rezar pra Deus proteger a casa, fazer aquele dia de oração. Fazer uma reza; rezar. Aí seu disse: - Faço. Se eu ficar bom eu faço. Se eu escapar eu convido a mulher. Com fé em Deus e em Nossa Senhora. Eu faço. Eu vou fazer no mês de agosto. Todo mês de agosto eu sinto uma coisa. Eu vou fazer essa reza pra trapar ${ }^{1}$ esse mês de agosto. Só vivo... toda vida é acidente com eu. Aí Contei pra ela e ela aceitou. Disse: - Pronto. Faça que aí é o caminho do céu! Eu fiquei fazendo a renovação todo ano (Depoimento de Horácio Coelho, 2017).

A realização da Renovação do Sagrado Coração de Jesus demanda gastos pelo costume secular de se fazer reformas ou a pintura da casa e de se oferecer um banquete e um lanche a todos os convidados que se fizerem presentes ao ato. Para poder arcar com os custos da festa os moradores se preparam economizando e criando animais como porco, galinha e bode para abater no dia da festa.

Pelas informações prestadas por Maria do Socorro Santana do Nascimento (Petinha), agente de saúde local, e reforçada pelas líderes comunitárias que atuam como rezadeiras nesses eventos, tomamos conhecimento que, atualmente, 52 famílias não realizam a festa. Diante das informações recebidas no cadastro da família, que indica que a renda familiar da maioria dos residentes é proveniente da aposentadoria e que poucos moradores da comunidade têm vínculo formal de trabalho e, mesmo os que têm não possuem renda superior a 1 salário mínimo e, acompanhando de perto as despesas geradas pela realização das festas de renovação, constatamos que somente 35 famílias realizam a renovação devido à falta de condições financeiras das demais, pois a realização da festa demanda muitos gastos.

Diante das evidências explicitadas na literatura acessada, nos atrevemos a opinar que, provavelmente, talvez o "padim" tenha introduzido em nossa cultura a realização das festas de Renovações com a intenção de adoçar a vida sofrida dos moradores do lugar com a realização da Consagração do Sagrado Coração de Jesus, adaptando-a a realidade local. De acordo com o depoimento de Padre

\footnotetext{
1 O morador usa a palavra "trapar" no sentido de atrapalhar a onda de azar que toma de conta de sua vida no mês de agosto. $O$ oitavo mês do ano é considerado azarado segundo a popular caririense.
} 
Paulo, o costume de se fazer grandes festas partiu dos fazendeiros e coronéis da época, mas, pelas orientações do Padre Cicero, deveria ser servido somente o café com biscoito, produtos acessíveis aos moradores com baixo poder aquisitivo.

E, segundo Araújo (2011) o costume arraigou-se à cultura caririense e as Renovações são realizados até os dias atuais. Muitos dos moradores fazem a opção de realizar a consagração de seus lares nos dias de São João ou Natal e de santos de sua devoção como São José, São Francisco e Santa Luzia, ou pelos motivos antes identificados relativos a casamentos e natalícios. A sincronização das duas festas torna essas datas especiais para os moradores que participam do festejo.

Ao seguir o ritual da renovação, percebemos diferenças em relações as celebrações que acompanhamos na zona urbana de Crato. Muitas modificações sofridas com o decorrer do tempo, muitas delas relativas às questões de consumo. Destacamos algumas:

- As Renovações não são mais celebradas somente em datas de casamento e aniversário. Algumas são em homenagem ao santo de devoção da família. Gradativamente, as celebrações deixam de ser feitas à noite e vem sendo realizadas durante o dia por diversas razões: questão de segurança; pelo fato de que à luz solar facilita andar longas distâncias a pé; pelo cansaço causado todo um dia dedicado à celebração;

- O ritual da Renovação é realizado tanto por pessoas de ambos os sexos, sendo que as rezadeiras são moradoras da localidade e os homens vêm da cidade de Juazeiro do Norte;

- Antigamente, nas Renovações do Coração de Jesus na cidade de Crato serviam o "aluá"; suco feito com a casca do abacaxi que ficava a fermentar durante três dias. Havia a opção de se tomar chá ou café; caso a bebida, que era acondicionada em um grande pote $^{2}$ na sala de jantar, não agradasse. Interessante, porém, saber que, mesmo sendo plantadores de abacaxi, segundo depoimentos, o aluá nunca foi uma bebida apreciada pelos moradores do Minguiriba.

\footnotetext{
2 Pote: grande reservatório de água, feito de cerâmica onde, na comunidade Minguiriba, até hoje se conserva, preferencialmente, a água para o consumo.
} 
- Ao invés do aluá, chá ou café era servido com bolos, geralmente de puba ou milho e sequilhos, estes foram substituídos por biscoitos e sequilhos ou salgados, nas residências com moradores que tenham mais condições, pois são mais trabalhosos para fazer e saem mais caro se decidir comprar feito;

- O lanche era colocado em pratinhos em torno da mesa. No Minguiriba colocam em bandejas e as pessoas vão pegando ou em estojos plásticos fechados e entregues um a um, junto com um pequeno refrigerante, o que facilita na hora de servir.

Percebemos que as Renovações fazem parte da tradição da comunidade do Minguiriba e vem se resinificando com o tempo, porém, é um costume que pode vir a extinguir-se. A afirmativa baseia-se no fato de que a festividade no passado era realizada em todas as residências e hoje os festejos são realizados somente em 38 das 87 famílias residentes no sítio. Atribuímos esse baixo número de adeptos ao costume as difíceis condições de vida na Chapada do Araripe, ainda castigada por longos períodos de seca, onde grande parte da comunidade sobrevive de uma aposentadoria e há a inexistência de empregos formais. A ajuda nas subsistências vem por intermédio da agricultura popular, que é fragilizada pela falta de água que assola a localidade.

Além das condições climáticas e financeiras, outros fatores ameaçam a descontinuidade dos costumes de se fazer renovação no Sítio Minguiriba. Segundo depoimento dos moradores, não há um interesse visível por parte dos mais jovens de dar uma continuidade ao costume. Gostam de participar, mas se alguém preparar para eles, porém se depender de eles realizarem a festa, acreditam que a tradição vai desaparecer com o tempo.

\section{MAPA RITUALÍSTICO DAS RENOVAÇÕES DO SAGRADO CORAÇÃO DE JESUS}

A Renovação do Sagrado Coração de Jesus pode ser considerada o traço mais marcante de identidade dos moradores do Sítio Minguiriba, pelo fato de todas as famílias tradicionais da comunidade realizarem os festejos em suas 
residências. Em depoimento, o Padre Paulo afirma que

O território da Minguiriba que não tinha assistência do padre, não tinha assistência paroquial, até hoje, por isso que é muito forte aqui na Minguiriba a religiosidade popular. Pela ausência do sacerdote, pela ausência da igreja, o próprio povo da comunidade buscava a religiosidade popular como forma de rezar, de entrar em sintonia com Deus, de fortalecer a sua espiritualidade e de trabalhar a dimensão humana (Depoimento de Pe. Paulo, 2018).

O ritual de preparação e da Renovação da Consagração do Sagrado Coração de Jesus, pelo fato de ser constante e repetitivo em todos os lares e contar com a participação em massa de todos os moradores contribui para a formação das memórias individuais, coletivas e sociais do grupo.

No Sítio Minguiriba, nos contou Dona Lourdes que a primeira Renovação da Consagração ao Sagrado Coração de Jesus foi realizada na residência de uma senhora chamada (ouvir entrevista) há aproximadamente 80 anos atrás, contou com a participação de toda a comunidade circunvizinha e, desde então, passou a ser festejada em todas as residências tradicionais da comunidade.

\section{Imagem 1 - Decoração da sala do Santo}

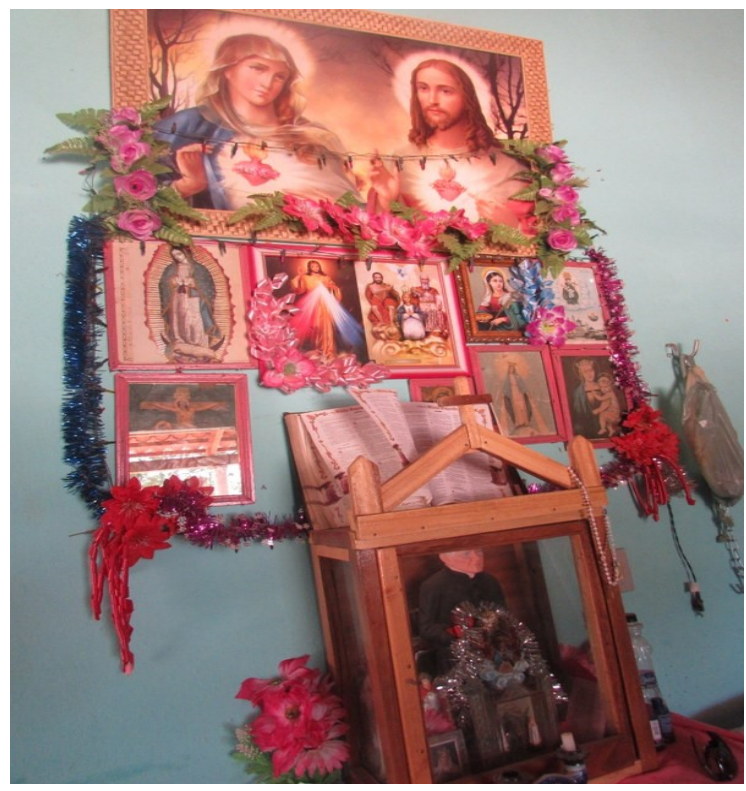

Fonte: Arquivo da pesquisa, (2017).

$\mathrm{Na}$ literatura vigente, encontramos a seguinte definição para Renovação do Sagrado Coração de Jesus:

As Renovações dos Sagrado Coração de Jesus, consistem em prática ritual instituída pelo Padre Cícero e caracterizada pela 
celebração anual, em domicílio, da renovação de contrato de proteção estabelecido com o santo, no momento de sua entronização na residência e da constituição do lugar na casa geralmente o primeiro cômodo - denominado sala do santo. A sala do santo funciona como um minialtar, com pequena mesa com função de aparador, para acender velas e depositar imagens esculpidas em madeira ou gesso. A mesinha é coberta com toalha especial, geralmente branca e delicada, a moda das toalhas de altar, junto a uma parede decorada com vários quadros que representam a imagem dos santos a quem a família tem devoção. As imagens do Sagrado Coração de Maria ocupam lugar central, caracterizando uma representação piedosa do sacrifício dos santos por seus protegidos que aparece tanto no semblante quanto na própria representação do coração exposto e sangrento da figura. Segundo Figueiredo (1998, p.123), "renovando a consagração da família à imagem do Coração de Jesus, renovam-se as esperanças no futuro da família, renovam-se os laços entre os vivos e entre os mortos: a renovação é um rito sacrificial e festivo, cuja liturgia ocorre no seio da família, sai dela como invocação e volta para ela como redenção [...] como potência para continuar a vida" (CORDEIRO, 2011, p. 47).

A decoração da "sala do Santo" traz as paredes enfeitadas com imagens de sua devoção rodeado de flores, às vezes com um pequeno oratório de madeira sobre uma mesa coberta por uma toalha e repleta de estátuas e/ ou quadros. Dentre estas imagens sempre encontramos o santo canonizados pela fé do povo romeiro: o Padre Cícero Romão Batista.

O mapa do ritual, passo a passo, pode ser descrito da seguinte forma:

$1^{0}$ - Parentes e amigos são convidados para a primeira vez que a Consagração do Sagrado Coração de Jesus é realizada. O convite é vitalício enquanto houver a celebração naquela casa. Novos convites somente para quem não faz parte do convívio familiar e não sabem e não têm conhecimento da data da realização daquele evento naquela residência;

$2^{\circ}$ - Limpeza dos quadros, troca dos enfeites anteriores por novos;

$3^{\circ}$ - Na véspera da renovação são temperadas as carnes;

$4^{\circ}-6 h, 12 h$ e $18 \mathrm{~h}$ estouram de 3 a 6 fogos como lembrete que é dia de renovação;

$5^{\circ}$ - Logo cedo começam a preparação das comidas para o almoço e/ou jantar, além de bolos, biscoitos, sequilhos e salgados e sucos ou refrigerantes para o lanche. Muitos dos convidados participam tanto do almoço, quanto do jantar; 
$6^{\circ}$ - No início da renovação são soltos de 1 a 3 fogos;

$7^{\circ}$ - Os homens sentam no terreiro da casa, à sombra das árvores, alguns prestam atenção ao ritual, outros conversam, alheios a celebração, enquanto as crianças brincam em volta da casa e as mulheres participam do ritual realizado na sala do santo pela "beata", entoando louvores e fazendo orações;

$8^{\circ}$ - A celebração varia de $1 \mathrm{~h}$ a $1 \mathrm{~h}$ e meia, sem um tempo rígido controlado e iniciam a Consagração do Sagrado Coração de Jesus com a invocação da Santíssima trindade, rezando ou cantando;

$9^{\circ}$ - Após cada oração as mulheres cantam um louvor. Após cada cântico soltam 1 fogo;

$10^{\circ}$ - Ao entoarem o canto final escutamos uma rajada de fogos;

$11^{\circ}$ - Após a consagração é servido um lanche que varia de casa para casa: bolos, biscoitos, café, chá, suco ou refrigerante, ao agrado do convidado; $12^{\circ}$ - São servidas as crianças primeiramente, em seguida as mulheres e por último os homens;

$13^{\circ}$ - Depois do evento os convidados se reúnem no terreiro conversando, contando his/estórias. Alguns partem logo após o lanche.

\section{Imagem 2 - Mapa Ritualístico da Renovação}

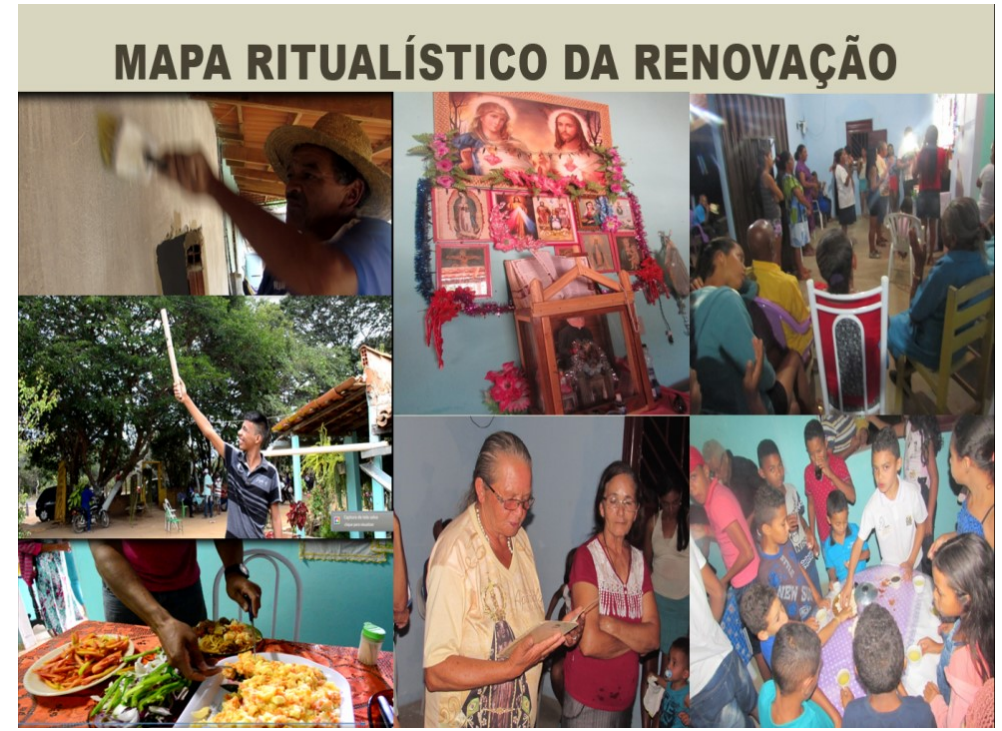

Fonte: Arquivo da pesquisa, (2017).

Sobre as fotos expostas esclareceremos na ordem de exibição, facilmente identificada na imagem acima: 
1. Miguel, esposo de Tontonha pinta o cômodo da casa recém construído para a renovação. Ainda serão colocadas as janelas e a tinta branca será coberta pela cor lilás;

2. Os fogos desempenham a função de convite e sinalização dos locais onde haverá Consagração do Sagrado Coração de Jesus.

3. Participam do almoço ou do jantar antes da renovação, todos aqueles que comparecerem ao local. É posta uma mesa farta com 3 e até 4 tipos de carnes diferentes, arroz, feijão, salada e macarrão, podendo ou não ser acompanhado de refrigerantes.

4. Maria é líder da comunidade e faz o papel da beata local. É quem reza as Renovações do Sagrado Coração de Jesus, cujo ritual traz caprichosamente copiado em um caderno pequeno gasto pelo tempo. Característica que também é apresentada pela também líder Cícera, que também possui os registros da renovação escrito a mão pelas mesmas razões apresentadas por Maria. Ela também organiza as missas que ocorrem uma vez por mês, aos domingos na capelinha de um dos cemitérios locais. D. Antônia, ao seu lado, é a dona da casa onde a renovação está sendo realizada.

\section{Imagem 3 - Manuscrito da Renovação do Sagrado Coração de Jesus}

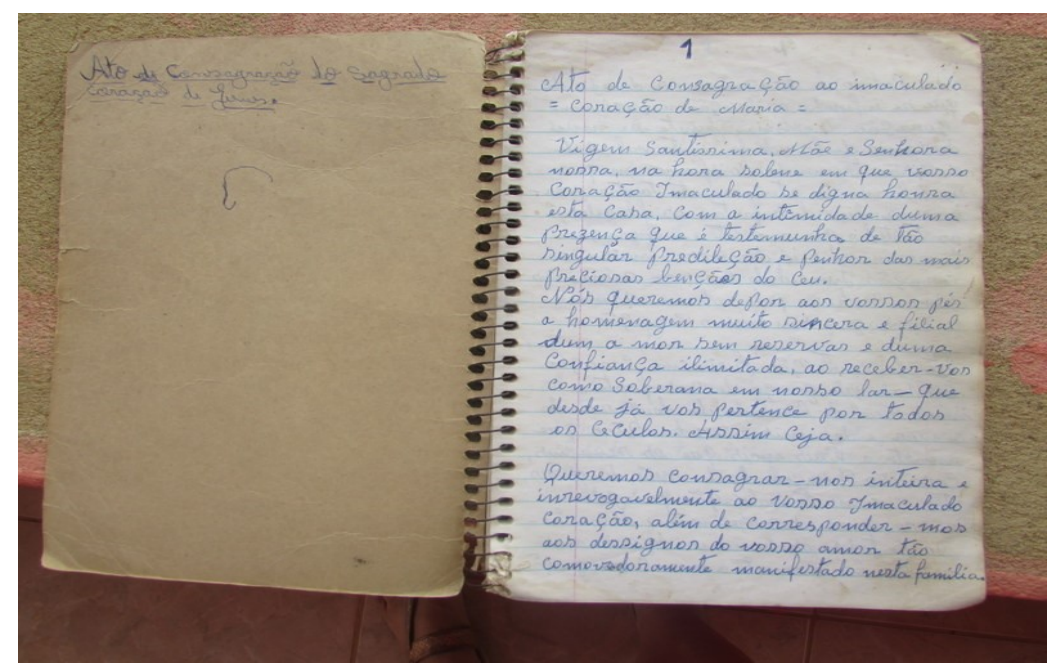

Fonte: Arquivo da pesquisa, (2017).

5. Antigamente as mulheres assistiam à renovação dentro de casa e os homens ficavam na parte externa. Este ano, na casa da Tontonha, na casa da Cícera e em outras celebrações percebemos que alguns 
homens participaram da reza na sala, junto das senhoras. Uma atitude inovadora na comunidade.

6. Biscoitos e chá de capim santo e erva cidreira, ou café são servidos na hora do lanche. As crianças demonstram ser, depois das brincadeiras, ser esse o momento mais esperado da festa.

Em uma das Renovações que participamos presenciamos a apresentação de duas mulheres do coco que animaram a tarde com bom humor e talento, uma delas era irmã do dono da casa. Ficamos sabendo nesse dia que nas Renovações de antigamente costumavam fazer apresentações folclóricas ao final dos rituais. Um costume que nunca presenciamos na cidade.

\section{CONCLUSÃO}

Em meio aos conflitos ideológicos relativos às questões religiosas e políticas que envolvem o dia a dia do Minguiriba, percebemos a importância das festas de renovação realizadas na comunidade. Estes festejos conservam o sentimento de pertencimento ao grupo e criam um elo que dá sustentabilidade à memória coletiva.

As narrativas das memórias dos acontecimentos cotidianos do passado e do presente, bem como as festividades religiosas realizadas dão suporte à criação de identidades da comunidade formada pelos remanescentes dos romeiros do Padre Cícero, assentados na Chapada do Araripe, entre os anos de 1900 e 1908, na parte que compreende uma pequena porção situada na cidade de Crato, no estado do Ceará, ao qual denominaram de Sítio Serra da Minguiriba.

\section{REFERÊNCIAS}

ARAÚJJ, Márcia Regina Soares de. Ritual do evento consagração solene do lar ao Sagrado Coração de Jesus: renovação. Caderno de Cultura e Ciência, ano VI, v.10, n. 2, dez. 2011.

ARAÚJO, Marivânia Conceição de. A teoria das representações sociais e a pesquisa antropológica. Revista Hospitalidade, v. 5, n. 2, p. 98-119, 2008. 
ARIAS, Patricio Guerrero. La cultura: estratégias conceptuales para comprender a identidad, ladiversidad, la alteridad y la diferencia. Escuela de Antropologia Aplicada UPS-Quito: EdicionesAbya-yala, 2002.

BAUMAN, Zygmunt. Comunidade: a busca por segurança no mundo atual. Rio de Janeiro: Jorge Zahar Editora, 2003.

BAUMAN, Zygmunt. Identidade: entrevista a Benedetto Vecchi. Rio de Janeiro: Jorge Zahar Editora, 2005.

BELTRAMI, André. Santa Margarida Maria Alacoque: a esposa do Sagrado Coração de Jesus, história da sua vida. 2. ed. São Paulo: Escolas Profissionais do Lyceu C. de Jesus, 1932.

BUENO, Barbara. Quando é o seu Onomástico? Disponível em: https://www.brasilnaitalia.net/2008/10/quando-e-o-seu-onomastico.html. Acesso em: 10 dez. 2018.

BRITO, A. S. Estudo da viabilidade de implantação de fossa verde em comunidade rural: tecnologia social para convivências no Semiárido, CratoCE. 99 f. 2015. Dissertação (Mestrado em Desenvolvimento Regional Sustentável) - Universidade Federal do Cariri - (UFCA), PRODER, Juazeiro do Norte, 2015.

CAMPOS, Luiz Fernando de Barros; VENÂNCIO, Ludmila Salomão. O objeto de estudo da ciência da informação: a morte do indivíduo. Inf. Inf., Londrina, v.11, n.1, 2006. Disponível em:

http://www.uel.br/revistas/uel/index.php/informacao/article/view/1720/1471.

Acesso em: 10 dez. 2018.

CANCLINE, N. G. Culturas Híbridas. 4. ed. 7 reimp. São Paulo: Editora da Universidade de São Paulo, 2015.

CANEVACCI, M. Sincretismos: uma exploração das hibridações culturais. São Paulo: Studio Nobel,1996.

CRUZ, Adriano. A identidade no documentário Elena. REBECA: Revista Brasileira de Estudos de Cinema e Audiovisual, v. 3, n. 1, 2014. Disponível em: https://rebeca.socine.org.br/1/article/view/157. Acesso em: 09 dez. 2018.

CORDEIRO, Maria Paula Jacinto. Entre chegadas e partidas: dinâmicas das romarias em Juazeiro do Norte. Fortaleza: Editora Imeph, 2011.

CUCHE, Denys. A noção de cultura nas ciências sociais. Bauru: EDUSC, 1999.

GUILOUSKI, Borres; COSTA, Diná Raquel D. da. Ritos e rituais: Inclusão ou exclusão: sobre a disposição do gênero no ritual de renovação do Sagrado Coração de Jesus. 2. Simpósio da Associação Brasileira de História das religiões, 2015. 
GUIMARÃES, T. S. Padre Cícero e a nação romeira: estudo psicológico da função de um "santo" no catolicismo popular. Fortaleza: IMEP H, 2011.

GONDAR, Jô. Quatro proposições sobre memória social. In: GODAR, Jô; DODEBEI, Vera. O que é memória social. Rio de Janeiro: UNIRIO, 2005.

HALL, S. Representation: cultural representations and Signfying practice. Edited by Stuart Hall, Sage publication, London. Thousands Oak. New Delhi. 1997.

HALBWACHS, M. A memória coletiva. São Paulo: Centauro, 2004.

IPECE. Instituto de Pesquisa e Estratégia Ecônomica do Ceará. Disponível em: http://www.ipece.ce.gov.br/perfil_basico_municipal/2016/Crato Acesso em: 06 jul. 2018.

\section{MADEIRA, Vanessa. Manifestações culturais constituem patrimônio de} diversidade na capital. 2017. Disponível em: http://diariodonordeste.verdesmares.com.br/cadernos/cidade/manifestacoesculturais-constituem-patrimonio-de-diversidade-na-capital-1.1080528. Acesso em: 31 out. 2018.

POLLAK, Michael. Memória e Identidade Social. Revista Estudos Históricos, Rio de Janeiro, v. 5, n. 10, p. 200-215, 1992. Disponível em: http://bibliotecadigital.fgv.br/ojs/index.php/reh/article/view/1941/1080 Acesso em: 11 jan. 2018.

SAMPAIO, L. C. A Renovação do Sagrado Coração de Jesus. 2002. 103 f. Dissertação (Mestrado em História do Brasil) - Curso de Pós-Graduação em História do Brasil - URCA. Crato - CE, 2002.

SANTOS, R. J. Inclusão ou exclusão: sobre a disposição do gênero no ritual de renovação do Sagrado Coração de Jesus. In: SIMPÓSIO DO NORDESTE DA ABHR, 2015. Disponível em:

http://www.abhr.org.br/plura/ojs/index.php/anais/article/viewFile/1284/1107 Acesso em: 03 mar. 2018.

TEIXEIRA, Joaquim de Sousa. Festa e identidade. Lisboa: Comunicação \& Cultura, n. 10, p. 17-33, 2010. Disponível em:

http://comunicacaoecultura.com.pt/produto/comuniccao-cultura-n-o-10/ Acesso em: 12 dez. 2018.

TOLOVI, Carlos Alberto. Mito, religião e política: Padre Cícero e Juazeiro do Norte. Curitiba: Editora Prismas, 2017.

WOODWARD, Kathryn. Identidade e diferença: uma introdução teórico e conceitual. In: SILVA, Tomaz Tadeu da (org.). Identidade e diferença: a perspectiva dos estudos culturais. Petrópolis: Vozes, 2000. 


\title{
THE RELIGIOUS FESTIVAL OF THE MINGUIRIBA SITE- CRATO-CE
}

\begin{abstract}
Introduction: It presents the religious festivals as symbolic events associating culture and identity in the Social Sciences. The construction of an identity, with characteristics pertinent to the collective denoted in representations, are rich and significant elements linked to individual or collective memory, such as customs, knowledge, places, rhythms, celebrations, legends and rites that, when adopted by a group, perpetuate and become sources of identity. Objective: to expose the renewal of the Sacred Heart of Jesus in the Minguiriba Site as narratives of the memories of the daily events of the past and the present. Methodology: it was a bibliographical review and interviews with the residents of the Site. Results: expose the results obtained. Conclusions: it was concluded that the religious manifestations preserve the sense of belonging of a group and create a link that gives sustainability to the collective memory.
\end{abstract}

Descriptors: Memory. Religious Manifestations. Minguiriba site - Crato - Ceará.

\section{EL FESTIVAL RELIGIOSO DEL SITIO MINGUIRIBA- CRATO-CE}

\begin{abstract}
RESUMEN
Introducción: presenta los festivales religiosos como eventos simbólicos que asocian cultura e identidad en las ciencias sociales. La construcción de una identidad, con características pertinentes al colectivo denotado en representaciones, son elementos ricos y significativos vinculados a la memoria individual o colectiva, tales como costumbres, conocimientos, lugares, ritmos, celebraciones, leyendas y ritos que, cuando son adoptados por un grupo, perpetuar y convertirse en fuentes de identidad. Objetivo: exponer la renovación del Sagrado Corazón de Jesús en el Sitio de Minguiriba como relatos de los recuerdos de los acontecimientos cotidianos del pasado y el presente. Metodología: fue una revisión bibliográfica y entrevistas con los residentes del Sitio. Resultados: exponer los resultados obtenidos. Conclusiones: se concluyó que las manifestaciones religiosas preservan el sentido de pertenencia de un grupo y crean un vínculo que da sostenibilidad a la memoria colectiva.
\end{abstract}

Descriptores: Memoria. Manifestaciones religiosas. Sitio Minguiriba - Crato - Ceará.

Recebido em: 07.07.2019

Aceito em: 09.09.2019 